\title{
Localization of Proliferating Cell Nuclear Antigen, Vimentin, c-Fos, and Clusterin in the Postischemic Kidney

\author{
Evidence for a Heterogenous Genetic Response among Nephron Segments, \\ and a Large Pool of Mitotically Active and Dedifferentiated Cells
}

Ralph Witzgall, Dennis Brown, Cordula Schwarz, and Joseph V. Bonventre

Renal Unit, Medical Services, Massachusetts General Hospital East, Charlestown, Massachusetts 02129; Departments of Medicine and Pathology, Harvard Medical School, Boston, Massachusetts 02114; and Harvard-Massachusetts Institute of Technology Division of Health Sciences and Technology, Cambridge, MA 02139

\begin{abstract}
The mechanisms leading to the recovery of the kidney after ischemic acute renal failure are poorly understood. To explore the role played by mitogenesis and dedifferentiation in this repair process and to identify whether the genetic response of the nephron segments reflects the level of susceptibility to injury, the temporal and nephron segment expressions of various proteins implicated in mitogenesis, differentiation, and injury were determined. Proliferating cell nuclear antigen (PCNA), a marker for the $G_{1}-S$ transition in the cell cycle and hence mitogenesis, was detected primarily in the $\mathrm{S3}$ segment of the proximal tubule, with maximal expression at $2 \mathrm{~d}$ postischemia. Vimentin, normally present in mesenchymal cells but not epithelial cells, and hence a marker for the state of differentiation, was prominently expressed in the $\mathrm{S} 3$ segment $2-5 \mathrm{~d}$ postischemia. In the $\mathbf{S 3}$ segments in the outer stripe of the medulla cells that stained positively for PCNA also stained positively for vimentin. Clusterin, a marker for cell injury, was expressed primarily in the S3 segment and in the distal tubule with distinct staining patterns in each segment. None of the cells that stained with clusterin antibodies were positively stained with PCNA or vimentin antibodies. Likewise, none of the PCNA or vimentin-positive cells expressed clusterin at detectable levels. Thus, in the $\mathrm{S3}$ segment, where there is significant ischemic injury, surviving cells express markers indicating that they undergo mitogenesis and dedifferentiate in the postischemic period. While there is some expression of c-Fos in the S3 segment, c-Fos was expressed predominantly, at 1 and $3 \mathrm{~h}$ postischemia, in the nuclei of the distal nephron, particularly in the thick ascending limb. The data support the view that the mature renal $\mathrm{S} 3$ segment epithelial cell can be a progenitor cell. ( $J$. Clin. Invest. 1994. 93:2175-2188.) Key words: acute renal failure $\bullet$ gene expression $\bullet$ ischemia $\bullet$ kidney $\bullet$ tissue repair
\end{abstract}

\section{Introduction}

The pathophysiological processes responsible for cell death and organ dysfunction secondary to ischemic acute renal failure

Address correspondence to Dr. Joseph V. Bonventre, Suite 4002, Massachusetts General Hospital East, 149 13th Street, Charlestown, MA 02129.

Received for publication 9 December 1993.

J. Clin. Invest.

(C) The American Society for Clinical Investigation, Inc.

$0021-9738 / 94 / 05 / 2175 / 14 \$ 2.00$

Volume 93, May 1994, 2175-2188 remain poorly understood $(1,2)$. Even less is known about the factors that are important for recovery of kidney function. In contrast to the heart and brain, where ischemia results in permanent cell loss, the postischemic kidney has the ability to restore structure and function completely. Yet in many cases the recovery is delayed or does not occur at all, and the persistence of the renal failure contributes to a high mortality rate $(\sim 40 \%)$ which has not changed significantly over the last 40 years (3). In order to develop strategies to hasten recovery, a more complete understanding of the cellular mechanisms involved in kidney repair is necessary.

There is controversy regarding the degree to which the pathophysiology of acute renal failure is related to loss of tubular cell polarity $(4,5)$, cell loss with tubular obstruction, loss of epithelial barrier function and backleak of filtrate (6), enhanced tubular pressures $(7,8)$, and vasoconstriction of preglomerular vasculature (9). It is our hypothesis that, although a functional defect in epithelial polarity may play a role in mild ischemic injury, cell death is an important component of acute ischemic renal failure, and therefore cellular proliferation and repair are necessary for restoration of the functional characteristics of the epithelium. If tubular cells divide, then another important question is whether all surviving cells have the potential to dedifferentiate, divide, and then redifferentiate into mature tubular cells or whether the replacement of the tubular epithelium is due to the action of only a few undifferentiated stem cells.

Experiments were designed to determine whether mitogenesis and dedifferentiation play important roles in the kidney response to ischemia and to determine whether only a few cells or many of the remaining viable cells are involved in the response. The postischemic kidney was evaluated for the appearance of histochemical markers of cell cycle progression, state of differentiation, and cell injury. We also evaluated the temporal characteristics of the dedifferentiation process relative to epithelial cell entrance into the cell cycle.

Proliferating cell nuclear antigen (PCNA), ${ }^{1}$ a DNA polymerase $\delta$-associated protein, was used as a marker for cell proliferation. PCNA-labeled nuclei identify a population of cells in late $G_{1}$ and early $S$ phases of the cell cycle (10). Vimentin was used as a marker of differentiation. Vimentin is an intermediate filament protein that is expressed in mesenchymal tissue but not in normal differentiated kidney epithelial cells. The expression pattern of c-Fos, the product of the $c$-fos immediate-early gene, was also evaluated. This gene is induced in a number of

1. Abbreviation used in this paper: PCNA, proliferating cell nuclear antigen. 

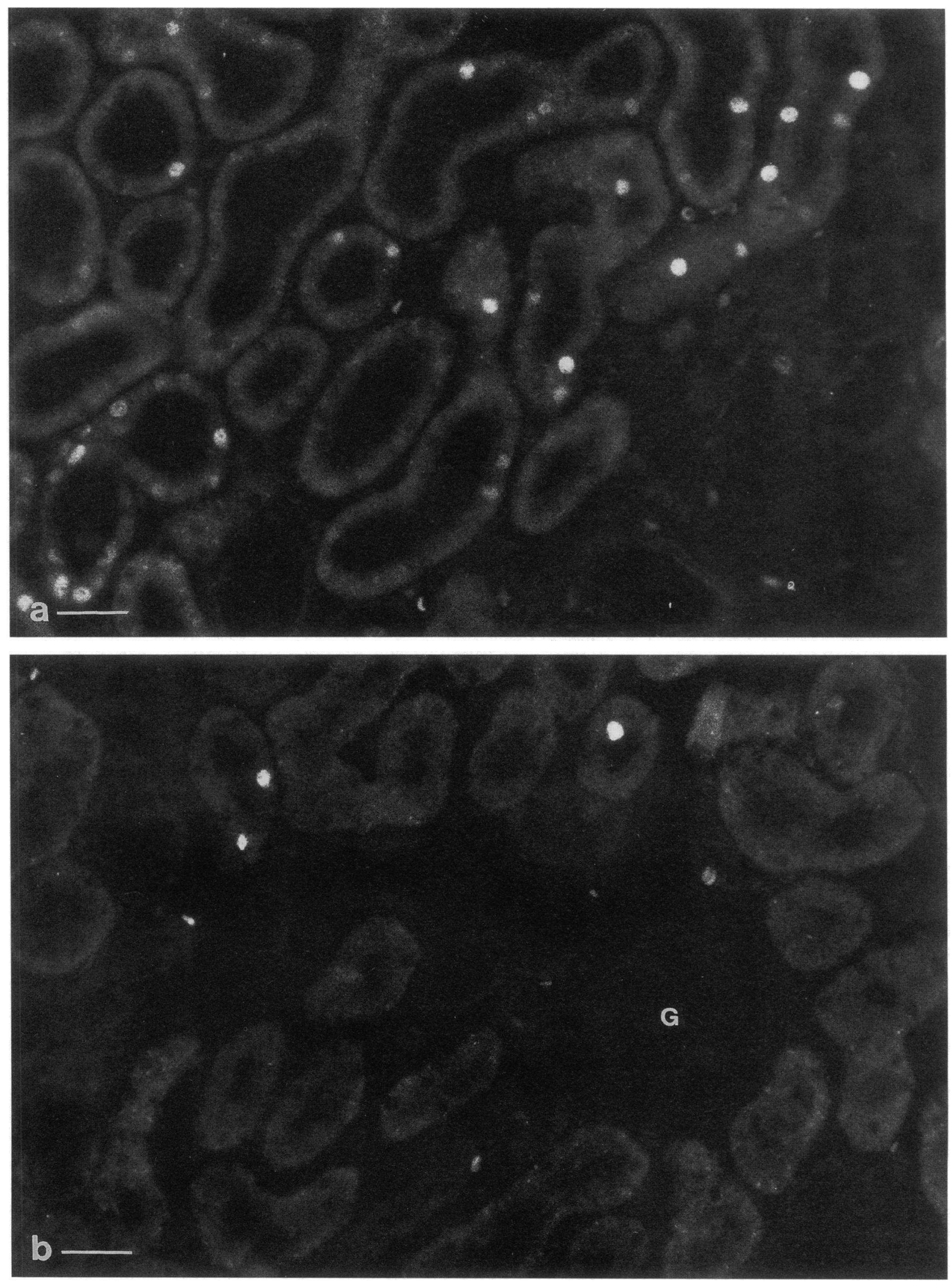

Figure 1. Cryostat sections of cortex from $(a)$ ischemic and $(b)$ contralateral control kidneys taken $48 \mathrm{~h}$ after ischemia and incubated with antiPCNA antibodies followed by goat anti-mouse FITC. Note the increased number of nuclei of proximal tubule segments that stain in the postischemic kidney when compared with the staining pattern in the contralateral kidney. G, glomerulus. Bars, $40 \mu \mathrm{m}$. 


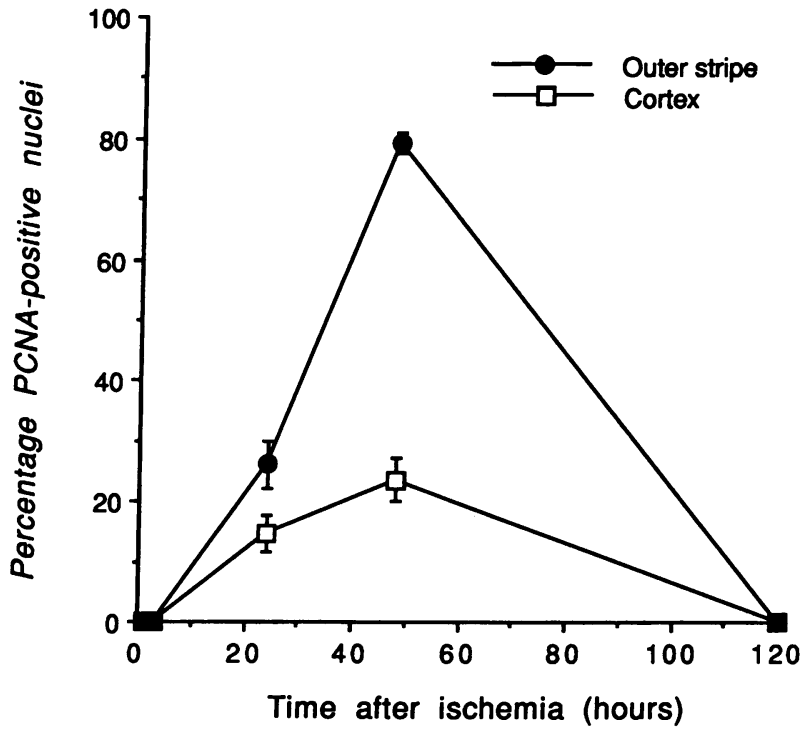

Figure 2. Time course of PCNA expression in proximal tubules in the cortex and outer stripe of the outer medulla after $\mathbf{4 0} \mathrm{min}$ of ischemia. This is a representative time course taken from one set of animals. In all cases the peak of PCNA expression occurred at $\sim 48 \mathrm{~h}$ postischemia although the percentage of positive nuclei varied somewhat at this peak time. At $120 \mathrm{~h}$ all cells were negative for PCNA. Bars indicate SEM. conditions in which cells are induced to divide or differentiate. Clusterin-also termed testosterone-repressed prostate message-2 (TRPM-2; 11), sulfated glycoprotein-2 (SGP-2), SP40,40 (12), dimeric acidic glycoprotein (DAG), gp 80, apolipoprotein $\mathrm{J}$, lipoprotein-associated protein, NA1/NA, serum complement cytolysis inhibitor (13), glycoprotein III (14)was also characterized. The gene encoding this protein has been associated with programmed cell death (apoptosis) (11) but is also found in some normal adult cells.

\section{Methods}

Animals. 190-275-g male Sprague-Dawley rats, purchased from Charles River Breeding Laboratories, Inc. (Wilmington, MA), were maintained under alternating 12-h cycles of light and dark. $10 \mathrm{ml}$ of $0.9 \%$ saline $\left(37^{\circ} \mathrm{C}\right)$ were administered intraperitoneally. Animals were anesthetized with an intraperitoneal injection of pentobarbitol (6.5 $\mathrm{mg} / 100 \mathrm{~g}$ of body weight). A left flank incision was made and the renal artery and vein were clamped with an microaneurysm clamp (Roboz Surgical Instrument Co., Washington, DC). The incision was closed temporarily until $40 \mathrm{~min}$ later when the clamp was removed. The incision was then sutured closed and after the stated time of reperfusion, both kidneys were fixed in situ for immunocytochemistry. $40 \mathrm{~min}$ of renal vascular occlusion results in a marked reduction in glomerular filtration rate as measured $1-3 \mathrm{~h}$ after reperfusion (15) and a marked increase in serum creatinine and blood urea nitrogen if the vascular occlusion is bilateral (16). Since one of the animal's kidneys is functionally intact, the model of unilateral ischemia used in these studies results
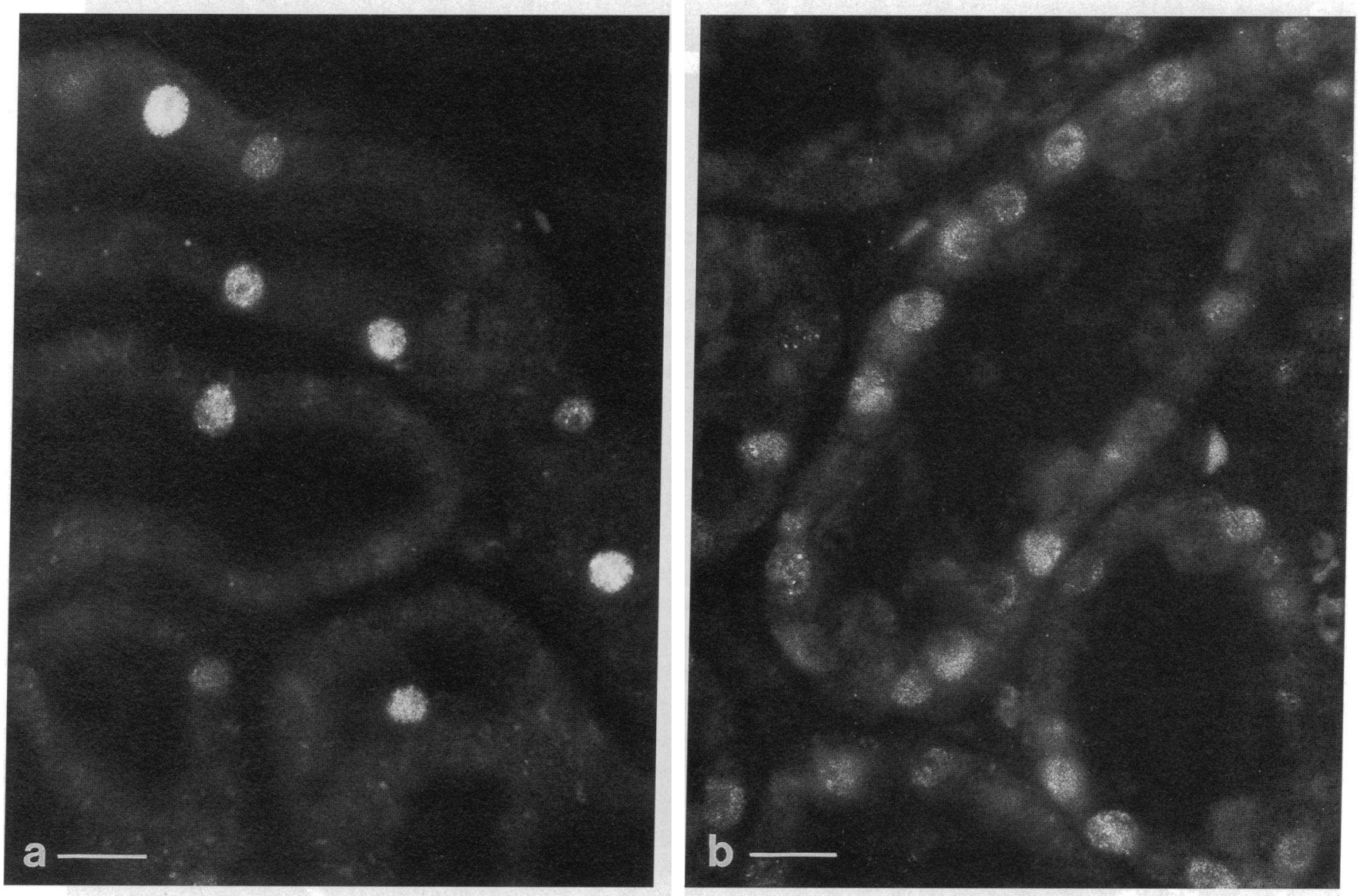

Figure 3. Cryostat sections of the $(a)$ cortex and $(b)$ outer stripe of the outer medulla of a postischemic kidney after $48 \mathrm{hr}$ of reperfusion. Sections were incubated with anti-PCNA antibodies. The number of stained nuclei is much greater in the S3 segment of the proximal tubule in the outer stripe, than in S1 and S2 segments located in the cortex. Bars, $20 \mu \mathrm{m}$. 

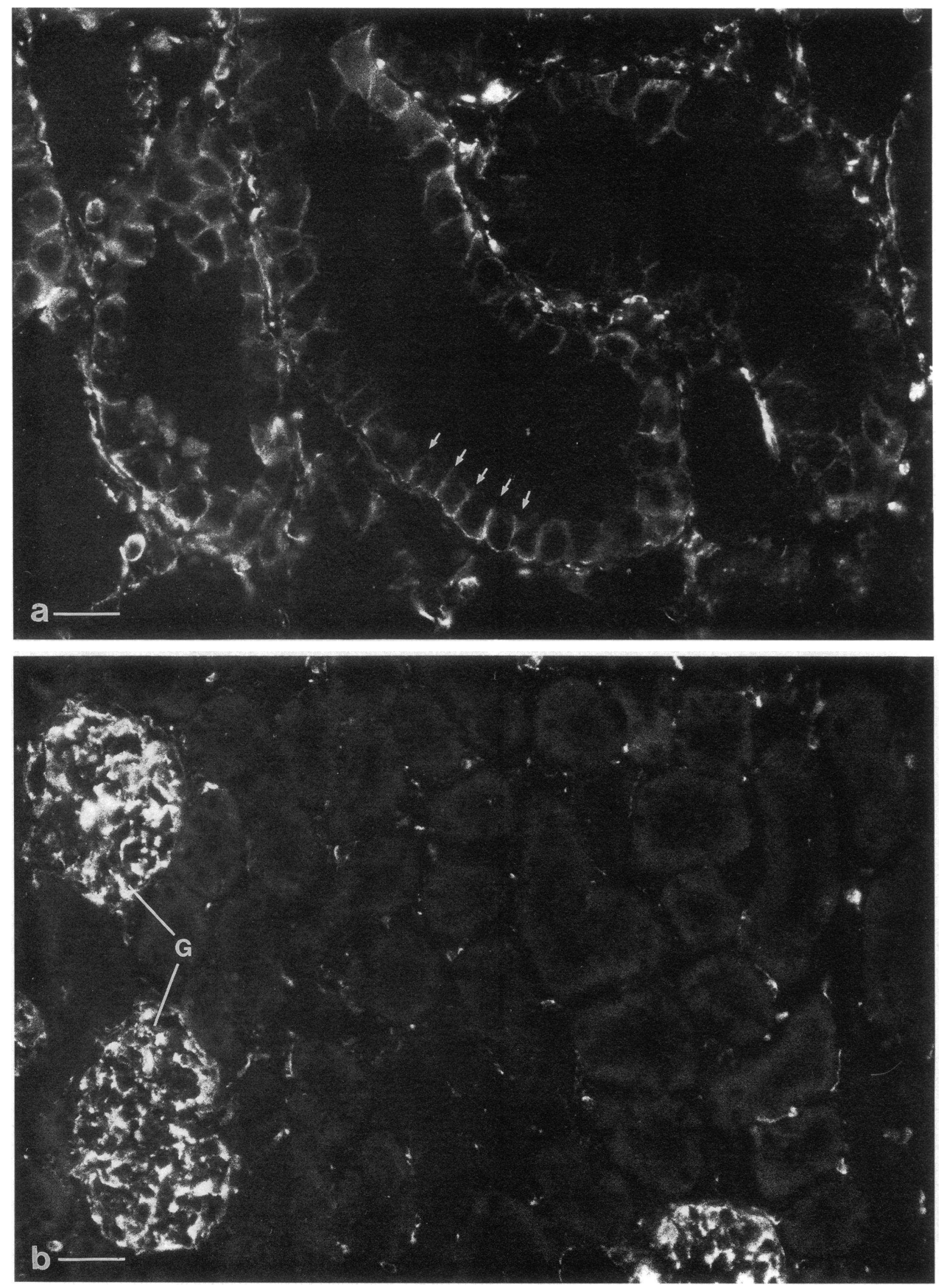


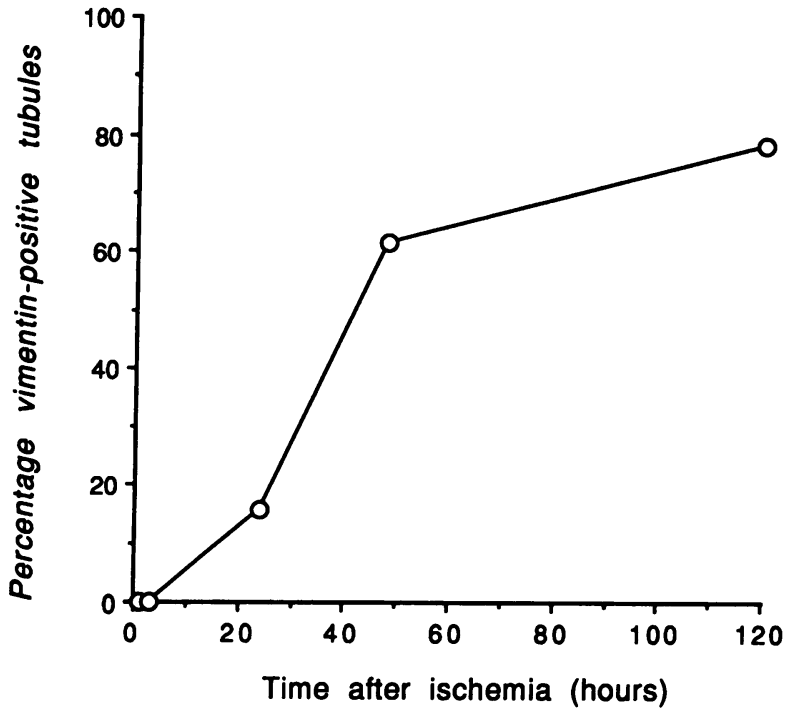

Figure 5. Time course of vimentin expression in the S3 segment of the proximal tubule after $40 \mathrm{~min}$ of ischemia. The number of vimentin-positive tubules remained high from 48 to $120 \mathrm{~h}$ after ischemia.

in only mild increases in plasma creatinine (from $0.52 \pm 0.02$ to 0.68 $\pm 0.08 \mathrm{mg} / \mathrm{dl})$ and blood urea nitrogen $(17.5 \pm 0.4$ to $20.5 \pm 1.5 \mathrm{mg} / \mathrm{dl})$ $($ mean \pm SEM) $(n=4)$.

Preparation of tissue. Rat kidneys were perfusion-fixed via the left ventricle with a paraformaldehyde-lysine-periodate fixative. After an initial 10-min fixation, the kidneys were kept in the fixative overnigh at $4^{\circ} \mathrm{C}$, rinsed with PBS, and kept in PBS containing $0.02 \%$ sodium azide until prepared for cryosectioning. For preparing $5-\mu \mathrm{m}$ frozen sections, tissue pieces were equilibrated for at least $1 \mathrm{~h}$ at room temperature in PBS containing $0.6 \mathrm{M}$ sucrose, embedded in OCT medium (Miles Laboratories, Naperville, IL), frozen in liquid nitrogen, and sectioned using a Reichert Frigocut cryostat (Leica Inc., Deerfield, IL). Sections were placed on SuperFrost Plus glass slides (Fisher Scientific Co., Fairlawn, NJ) and were either used immediately or kept at $-20^{\circ} \mathrm{C}$ until further processing.

\section{Immunocytochemistry}

Sections were incubated for $10 \mathrm{~min}$ in PBS $(0.9 \% \mathrm{NaCl}$ in $10 \mathrm{mM}$ sodium phosphate buffer, $\mathrm{pH} 7.4$ ) containing $1 \%$ BSA to reduce nonspecific background staining, followed by a 2 -h incubation at room temperature or an overnight incubation at $4^{\circ} \mathrm{C}$ with a $20-\mu \mathrm{l}$ drop of diluted specific antibody. After three 5-min rinses in PBS, sections were incubated for $1 \mathrm{~h}$ with goat anti-rabbit (diluted 1:60) or goat antimouse (1:30) IgG coupled to fluorescein isothiocyanate (Kirkegaard \& Perry, Gaithersberg, MD). Sections were then washed three times for 5 min in PBS and mounted in a medium consisting of $50 \% \mathrm{Tris} / \mathrm{HCl}$ buffer $(0.1 \mathrm{M}, \mathrm{pH} 8), 50 \%$ glycerol and $1 \%$-propyl gallate (Sigma Chemical Co., St. Louis, MO), which retarded quenching of the fluorescence. For some studies the tissue was also incubated for $1 \mathrm{~min}$ with 5 $\mu \mathrm{g} / \mathrm{ml}$ of the bisbenzimide dye Hoechst 33258 (Boehringer Mannheim Biochemicals, Indianapolis, IN) to stain the nucleus. For double staining of clusterin and PCNA or clusterin and vimentin, sections were incubated with both primary antibodies simultaneously and then, after PBS washes, incubated with goat anti-rabbit IgG coupled to fluores- cein (diluted 1:60) or goat anti-mouse IgG coupled to Cy3 (Jackson ImmunoResearch Laboratories, West Grove, PA), diluted 1:100. Sections were examined with a Nikon FXA photomicroscope equipped for epifluorescence (DonSanto Corp., Natick, MA) and photographed using Kodak TMAX 400 film pushed to ASA 1600.

\section{Antibodies}

Mouse monoclonal PCNA was obtained from Dako Corp., Carpinteria, CA (DAKO-PCNA, PC10, Lot 121). The antibody was made against recombinant rat PCNA and has been extensively characterized by Waseem and Lane (17). The PC10 antibody is an IgG2a isotype antibody that has high affinity for PCNA. The antibody reacts with a single band at $36 \mathrm{kD}$ on a Western blot of $\mathrm{S100} \mathrm{HeLa} \mathrm{cell} \mathrm{fractions.}$ Mouse anti-swine vimentin monoclonal antibody was also obtained from Dako Corp. (V9, IgG1). The antibody reacts only with vimentin on immunoblots of total cell extracts from human, rat, and mouse cells (18). Rabbit polyclonal antibodies specific for the amino acid sequence 214-226 (peptide P3-EEMSVASLDLTGG) region of the mouse c-Fos protein were obtained from Caltag Laboratories, San Francisco, CA. This antibody does not react with closely related proteins such as FosB (19). Monospecific rabbit polyclonal antiserum against rat clusterin was obtained from Dr. C Yan Cheng of The Population Council Center for Biomedical Research, New York (20). This antibody reacts exclusively with the two subunits (43 and $37 \mathrm{kD}$ ) of clusterin on immunoblots. Incubations with the primary antibody were carried out at dilutions of 1:20 except for anti-clusterin antibody, which was diluted $1: 500$.

\section{Quantification of Immunofluorescence}

$P C N A$. Serial sections were stained with antibodies to PCNA, as described above, and Hoechst 33258 to stain all the nuclei. The percentage of Hoechst positive nuclei that stained positively for PCNA was determined by direct examination of the tissue sections in the Nikon FXA fluorescence microscope. Staining was evaluated in cells in $20 \mathrm{~S} 3$ tubules, selected at random from each kidney.

Vimentin. When a particular S3 proximal tubular segment stained positively with antibodies to vimentin generally $>90 \%$ of the cells in that tubule stained positively. Therefore vimentin expression was quantitated as the number of vimentin positive tubules in the outer stripe as a function of time postischemia. Vimentin positive tubules were assessed in five randomly selected microscopic fields by direct examination in the fluorescence microscope with a $\times 20$ objective.

Clusterin. Clusterin expression was quantified using a confocal microscope (BioRad Laboratories, Richmond, CA). 5- $\mu$ m-thick cryostat sections, immunostained for clusterin, were optically sectioned at 0.5 $\mu \mathrm{m}$ intervals until the maximum level of fluorescence, judged subjectively for each individual section, was obtained on the monitor. At this point, the fluorescence intensity on screen was adjusted until the image was comparable to that observed under a conventional fluorescence microscope, and the set parameters (gain, dark level, aperture size) were maintained constant for each section subsequently examined. No further manipulation of the image was performed. Then, a thresholding procedure was used to apply yellow pseudocolor to pixels above a given pixel intensity, and the threshold was adjusted so that the yellowappearing pixels corresponded to the pattern of clusterin staining seen in the absence of imposed pseudocolor, with little or no background contribution. For each image, the percentage area occupied by colored pixels on the screen was calculated by the image analysis software, and was taken as a quantitative measure of clusterin staining in each section. This analysis was performed for five different fields from each section, each with an area of $267,632 \mu \mathrm{m}^{2}$.

Figure 4. Cryostat sections of postischemic (a) outer stripe of the outer medulla examined $5 \mathrm{~d}$ after reperfusion and $(b)$ outer cortex examined $1 \mathrm{~d}$ after reperfusion; sections were incubated with anti-vimentin antibodies. $(a)$ In the outer stripe there is basolateral staining of S3 segment epithelial cells. The arrows mark the lateral boundaries between cells. Bar, $20 \mu \mathrm{m}$. (b) In the cortex there is marked staining of the glomeruli but negligible staining of the S1 and S2 segments. Some interstitial cells are also stained. There was no detectable staining of the S1 or S2 segments at any time after reperfusion. This cortical staining pattern is similar to that found in non-ischemic control kidney. G, glomerulus; Bar, $40 \mu \mathrm{m}$. 

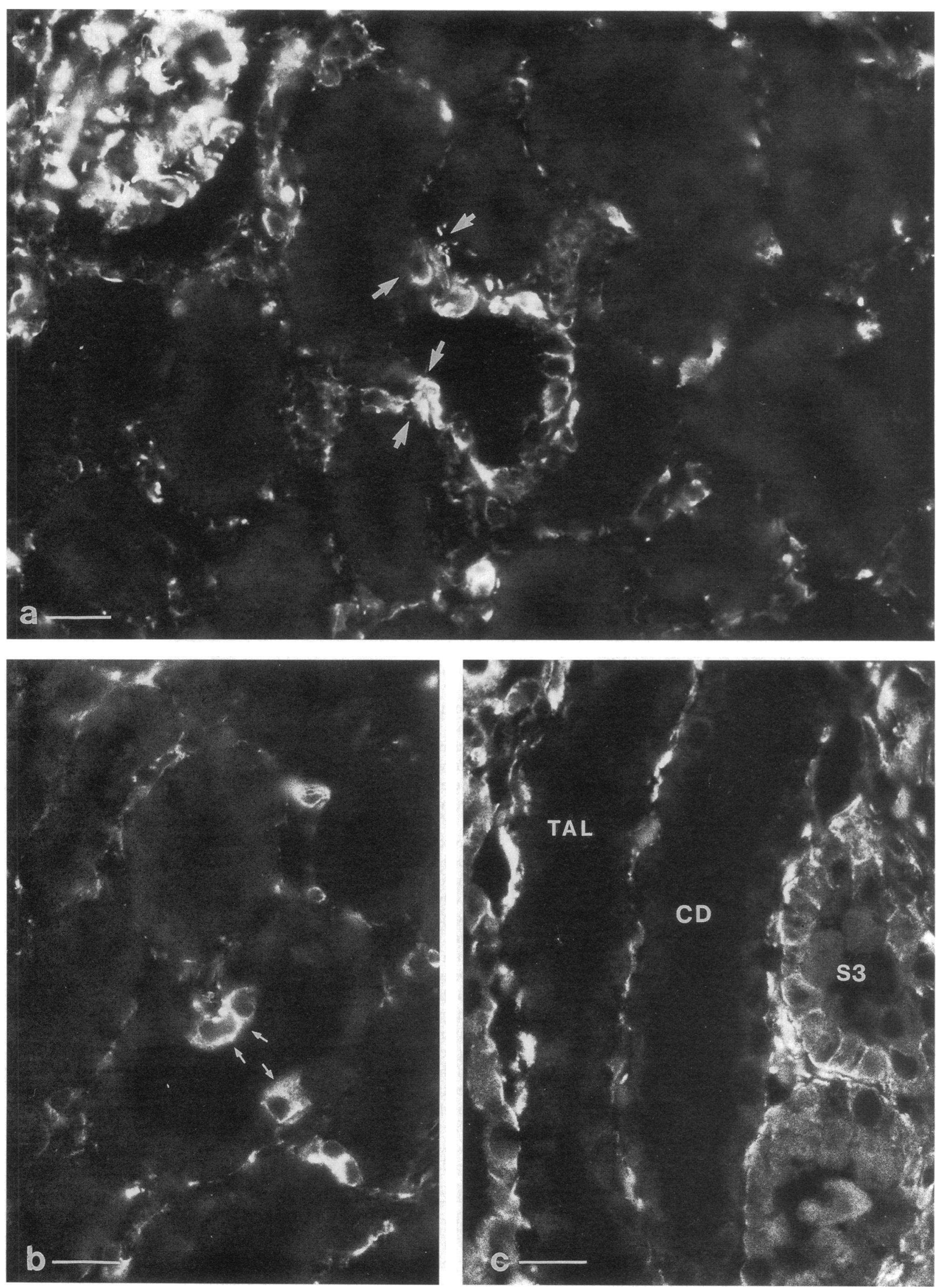

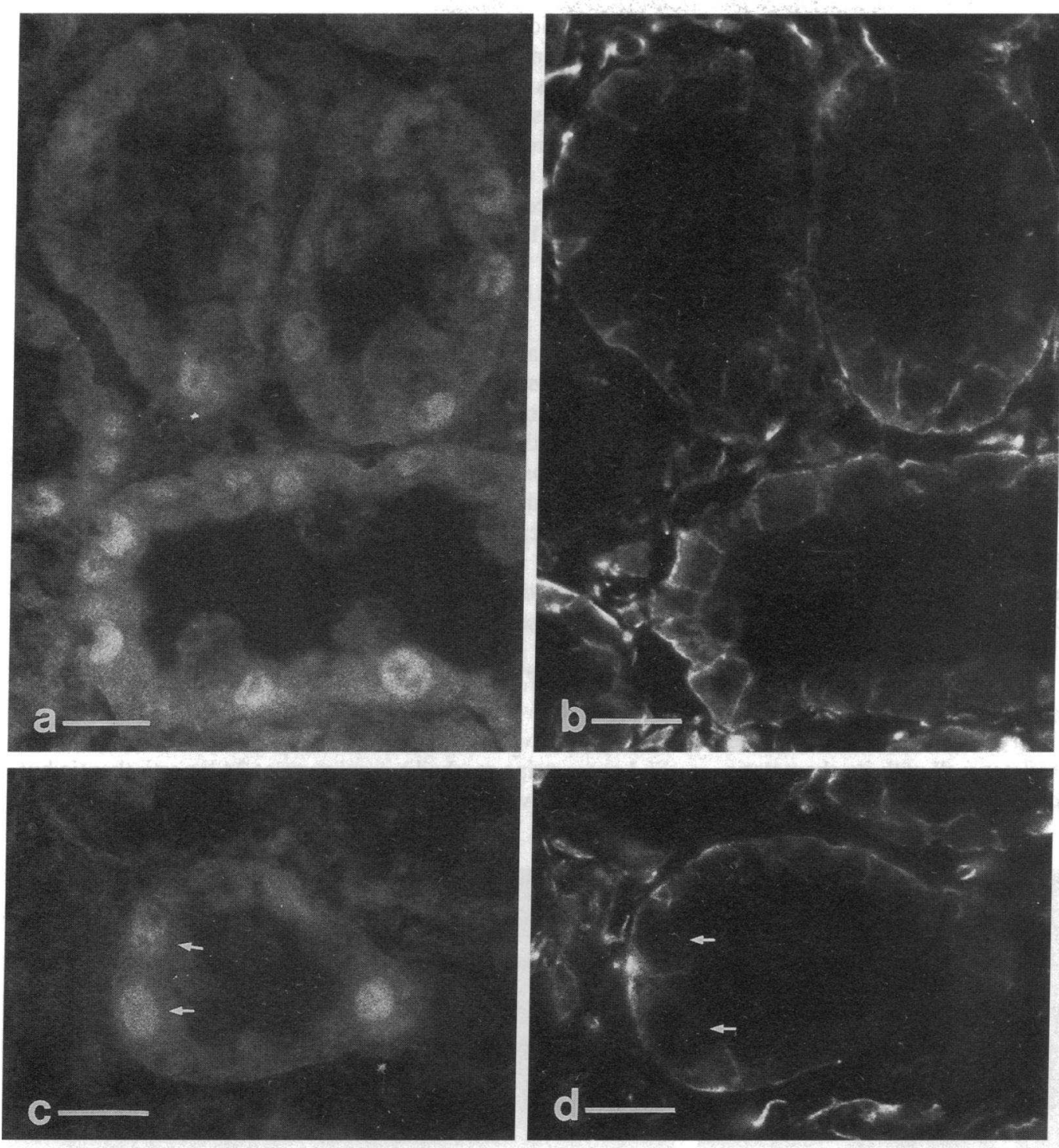

Figure 7. Two sets ( $a$ and $b, c$ and $d$ ) of serial cryostat sections of the outer medulla of postischemic kidneys taken $2 \mathrm{~d}$ after reperfusion and stained with antibodies to PCNA $(a$ and $c$ ) or vimentin $(b$ and $d)$. The same cells of the $\mathrm{S} 3$ segments of the proximal tubule stain in a nuclear pattern for PCNA and a basolateral pattern for vimentin. Arrows in $c$ and $d$ point to one example where the cells are PCNA and vimentin positive. Bars, $40 \mu \mathrm{m}$.

\section{Results}

Expression of PCNA. After ischemia, PCNA was detectable in the nuclei of epithelial cells of the cortical proximal tubule whereas in control kidney sections the number of labeled nuclei was considerably lower (Fig. 1). There were no differences in staining for PCNA or other proteins discussed below between control contralateral kidneys and sham-operated kidneys. PCNA-positive nuclei could already be detected after 24 $h$ of reperfusion, but the maximum level of expression was seen in the 48-h reperfused kidneys (Fig. 2). In the cortex, the number of fluorescent nuclei varied among different segments of the proximal tubule. There were more stained nuclei detectable in the $\mathrm{S} 3$ segment than in the $\mathrm{S} 1$ or $\mathrm{S} 2$ segments of the proximal tubule (Fig. 3, $a$ and $b$ ). In the outer stripe, many of the nuclei of the S3 segment cells were positive (Fig. $3 b$ ). This is the region where most of the ischemia-induced damage to tubule architecture occurred.

Expression of vimentin. Cells of mesenchymal origin in the interstitium expressed high levels of vimentin, as did glomerular mesangial cells in both postischemic (Fig. 4) and contralateral control kidneys (not shown). Vimentin was undetectable in epithelial cells from either sham-operated control kidneys, or contralateral kidneys from experimental animals. In contrast, epithelial cells in proximal tubules from ischemia-damaged kidneys showed a marked staining for vimentin that was first seen at $24 \mathrm{~h}$ (Fig. 4). Staining was apparent in a majority of viable outer stripe $S 3$ cells by $48 \mathrm{~h}$ and remained at approxi-

Figure 6. Cryostat sections of 2-d postischemic kidney cortex stained with anti-vimentin antibodies. (a) Some proximal tubules show an abrupt transition from negative to positive vimentin staining of epithelial cells as indicated by the arrows. This is interpreted to represent a transition from the S2 (negative) to S3 (positive) proximal tubule region. (b) Occasional vimentin-positive cells (arrows), presumably S3-like cells, were found in otherwise negative regions of $\mathrm{S} 2$ proximal epithelium. (c) In medullary rays, both thick ascending limbs $(T A L)$ and collecting ducts $(C D)$ showed no staining with anti-vimentin antibodies, whereas adjacent S3 segments expressed vimentin. Bar, $20 \mu \mathrm{m}$. 
mately this level to $120 \mathrm{~h}$ postischemia (Figs. 4 and 5). By $16 \mathrm{~d}$ postischemia there was little vimentin staining. The staining at 2-5 d postischemia was restricted to the S3 segment of the proximal tubule in the outer stripe of the outer medulla, and the pattern of staining indicated a basolateral plasma membrane localization in most positive cells (Fig. $4 a$ ). Staining was rarely observed at the apical pole of these cells. The segmentspecific expression of vimentin was strikingly demonstrated in sections where the S2-S3 transition region of the proximal tubules was identified. In these regions, we have previously demonstrated a similar remarkable cellular heterogeneity of staining for other proximal tubule antigens $(21,22)$. Fig. $6 a$ demonstrates part of a proximal tubule in which negative epithelial cells give way to positive cells, probably reflecting such an S2S3 transition. In other tubules, occasional positive cells, presumably S3-like cells, were found in an otherwise negative epithelium (Fig. 6 b). In medullary rays in the cortex (Fig. $6 c$ ), both thick ascending limbs and collecting ducts showed no staining with anti-vimentin antibodies. When serial sections were examined for PCNA and vimentin it was evident that cells in the S3 segments in the outer stripe of the medulla that stained positively for PCNA also stained positively for vimentin (Fig. 7).

Expression pattern of $c$-Fos. As determined by Northern blot analysis, $c$-fos is expressed very early and transiently after renal ischemia (23), which correlates well with its characteristics as an immediate-early gene. We examined tissue sections from ischemic rat kidneys 1 and $3 \mathrm{~h}$, and 1,2 , and $5 \mathrm{~d}$ after a 40-min ischemic insult, with an antibody to the c-Fos protein (Fig. 8). c-Fos staining was seen primarily in the nuclei of medullary thick ascending limbs of Henle in ischemic kidneys after 1 and $3 \mathrm{~h}$ of reperfusion with peak expression at $3 \mathrm{~h}$ (Fig. $8 a$ ). Some cells in medullary regions of the collecting duct (Fig. $8 a$ ) and some medullary proximal tubular (S3 segment) cells were also stained (Fig. $8 b$ ), as were a few interstitial cells and some cells possibly in the thin limbs of Henle. A definitive distinction between localization to the endothelial cells vs. thin limb cells was not possible at this level of resolution. Staining was not found in any epithelial cell type in the kidney cortex. At 24 $\mathrm{h}$ or more postischemia, no c-Fos staining was seen in any cell type. In sham-operated or contralateral kidneys, no c-Fos staining was detectable in any cell type at any time.

Expression of clusterin. In postischemic kidneys, clusterin was expressed strongly in cells of the distal convoluted tubule and the cortical thick ascending limb of Henle (Figs. 9 and 10). The staining appeared in a finely granular pattern predominantly located towards the apical pole of the positive cells. By contrast, S3 segments of the proximal tubule showed a much more intense staining for clusterin that in some cells appeared to fill most of the cytoplasm (Fig. 10). In many S3 segments of postischemic kidneys there were large casts that stained intensely positive for clusterin. Clusterin expression in the cortex and outer stripe reached a maximum at $24 \mathrm{~h}$ postischemia but remained elevated long after that (Fig. 11). Clusterin-positive
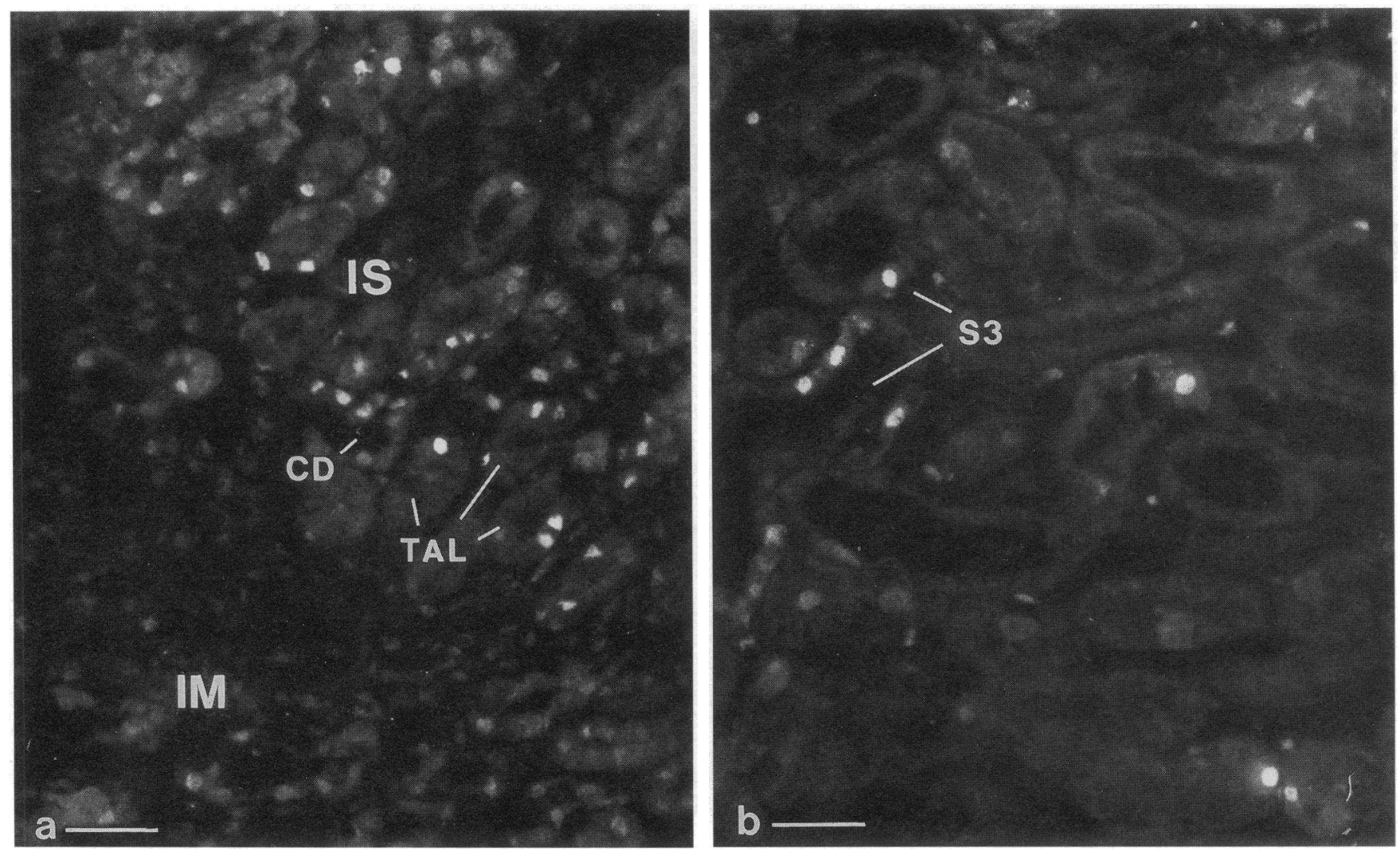

Figure 8. Cryostat sections of outer medulla of postischemic kidneys taken $3 \mathrm{~h}$ after reperfusion, stained with antibodies against c-Fos. $(a)$ The nephron segments in the inner stripe $(I S)$ of the outer medulla, whose cell nuclei were most predominantly stained, were thick ascending limbs $(T A L)$. There was also weaker staining of some collecting duct cells $(C D)$. There was less c-Fos expression in the inner medulla $(I M)$. $(b)$ Occasional S3 segment cells were also stained. Staining of the S3 segment cell nuclei was seen less often than in thick ascending limb cells. Bars, $40 \mu \mathrm{m}$. 

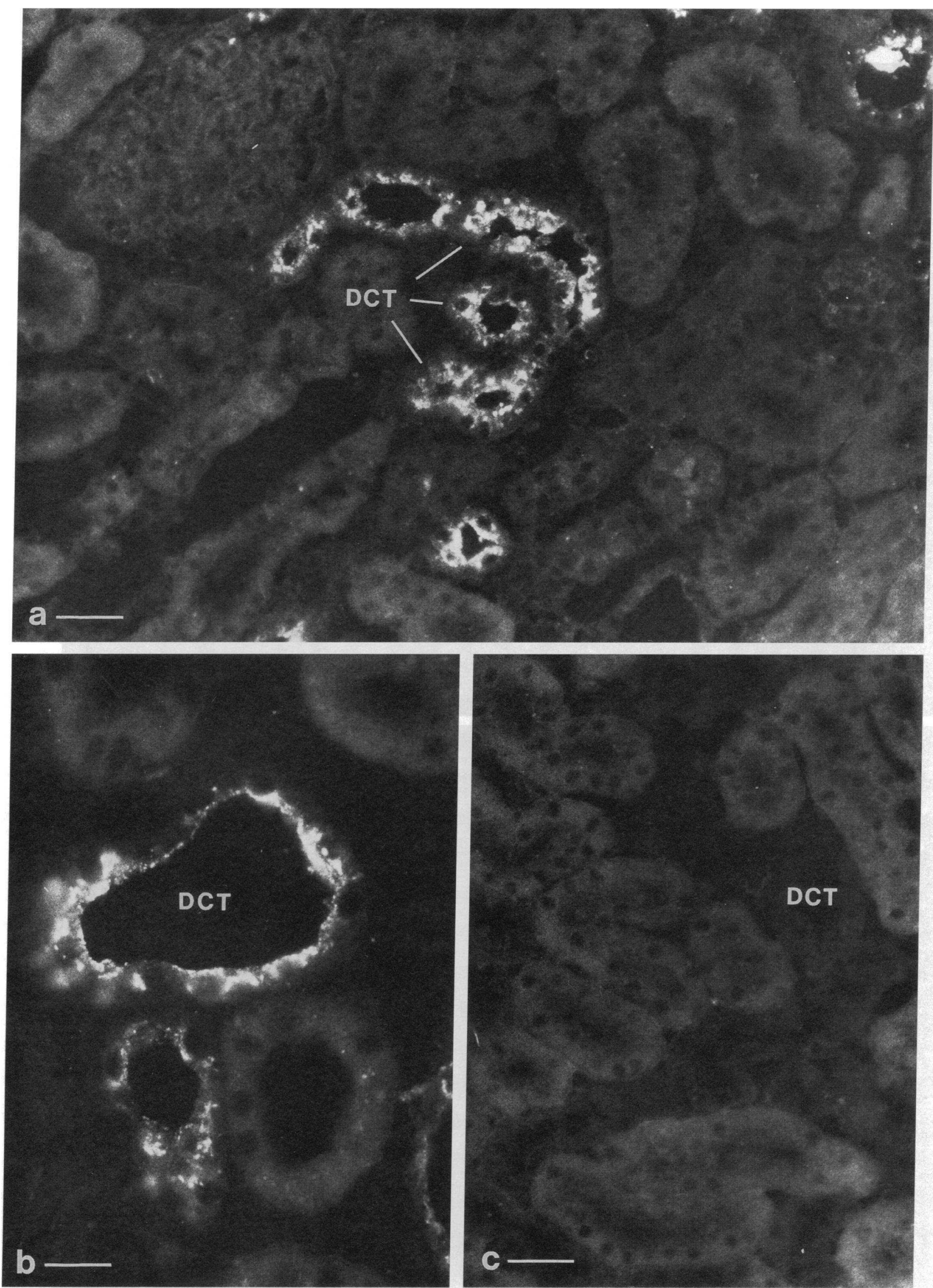

Figure 9. Cryostat sections of the cortex of $(a$ and $b)$ postischemic and $(c)$ contralateral control kidney taken $2 \mathrm{~d}$ after reperfusion and incubated with antibodies to clusterin. (a) Clusterin was expressed strongly in cells of the distal convoluted tubule (DCT) and the cortical thick ascending limb. Bar, $40 \mu \mathrm{m}$. (b) Higher magnification demonstrating a granular staining pattern, concentrated in the apical regions of the cells. Bar, $20 \mu \mathrm{m}$. (c) Staining was undetectable in the proximal and distal tubules of the contralateral, non-ischemic kidney. Bar, $40 \mu \mathrm{m}$. 


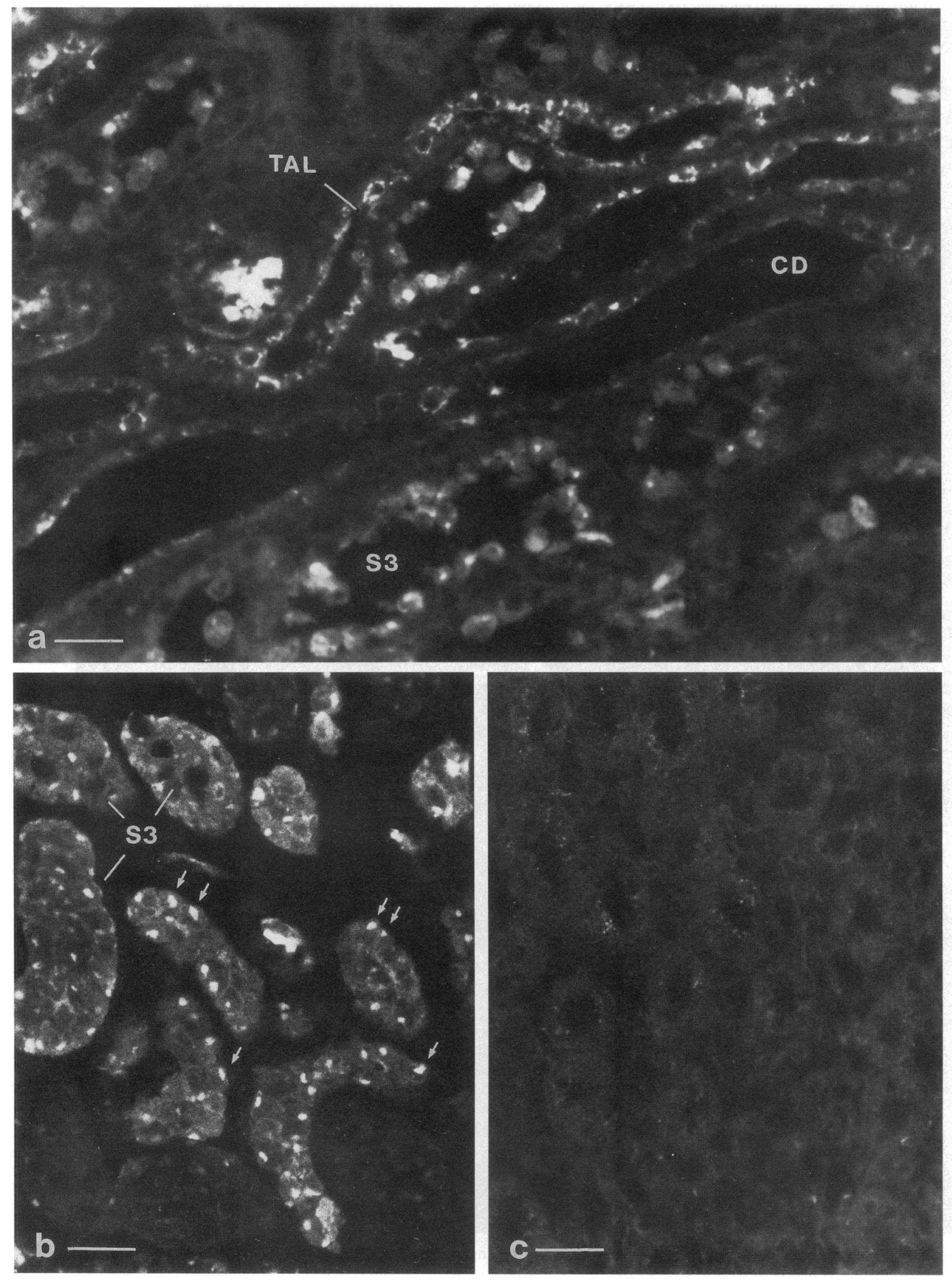




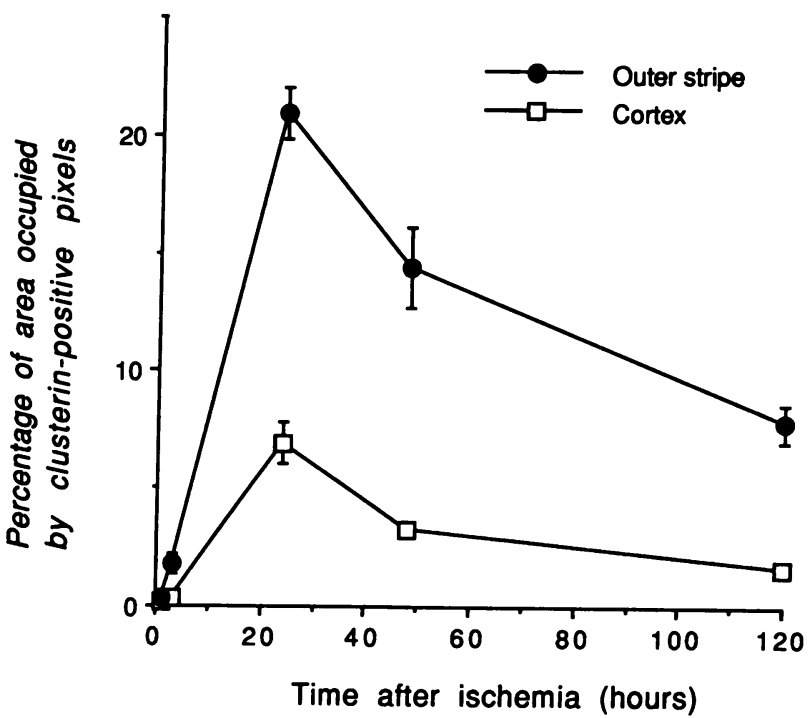

Figure 11. Time course of clusterin expression in the S3 segment of the proximal tubule in cortex and outer stripe of the outer medulla after $40 \mathrm{~min}$ of ischemia. The peak expression of clusterin occurred at $24 \mathrm{~h}$ postischemia. Clusterin expression was observed $120 \mathrm{~h}$ postischemia with residual clusterin positive debris within the tubular lumen up to $16 \mathrm{~d}$ postischemia (data not shown).

debris was seen in the lumen of $\mathrm{S} 3$ segments up to $16 \mathrm{~d}$ postischemia (data not shown). At that time many positive cells were present in the tubule lumen, probably representing dead or damaged cells. In some of these cells, a bright spot of clusterin staining was observed. Because of a possible relationship to apoptosis, we considered that this localized region of high intensity staining, observed in S3 segment cells, might represent the remains of the nucleus. However, double staining with the Hoechst nuclear stain showed that this bright spot did not contain any detectable DNA (Fig. 12). Cellular nuclei were readily detectable using this technique. In cells from contralateral and sham-operated control nonischemic kidneys, clusterin staining was considerably less intense, but was detectable in distal convoluted tubules and especially thick ascending limbs of Henle (Fig. $10 c$ ).

When the same sections of outer medulla were stained with antibodies to both PCNA and clusterin, two populations of cells were clearly segregated (Fig. 13). PCNA positive cells did not stain with clusterin antibodies and clusterin positive cells did not stain with PCNA antibodies (Fig. 13, $a$ and $b$ ). Individual outer medullary sections were double-stained with antibodies to vimentin and clusterin (Fig. 13, $c$ and $d$ ). None of the cells that stained with clusterin antibodies were positively stained with vimentin antibodies. Likewise, none of the vimentin-positive cells expressed clusterin at detectable levels.

\section{Discussion}

It has been reported that $\left[{ }^{3} \mathrm{H}\right]$ thymidine incorporation into the rat kidney is maximal at $\mathbf{4 8 - 7 2} \mathrm{h}$ after ischemia (24). There has been no definitive identification, however, of the cells undergoing cell division in the postischemic kidney. It is possible, for example, that whole-kidney thymidine incorporation may reflect interstitial or endothelial cell, rather than epithelial cell, proliferation. In order to understand better the process of restoration of kidney function it is important to identify which cells are proliferating and whether developmental paradigms are recapitulated in the recovering tissue.

In experiments in which total tissue mRNA levels are measured it has been found that the expression of several genes is altered after renal ischemic injury. These genes include $c-f o s$, $E g r-1$ (23, 25, 26), vimentin, clusterin (26), HSP-70 (27), JE and $K C(28), K i d-1$ (29), and the gene encoding the EGF receptor (30). However, since the kidney is so heterogeneous in structure and function and the extent of ischemic damage to the renal tubule so dependent upon the location of the tubule in the kidney, knowledge of changes in overall levels of mRNA or protein do not provide much insight into the role that particular proteins may play in the injury or recovery process. Although in some instances $(25,28)$ the localization of expression of these gene products has been defined, in most cases the tubule segments expressing the mRNAs and/or proteins has not been established.

PCNA is a cell-cycle regulated nuclear protein which is an important cofactor for DNA-polymerase $\delta(31,32)$. This protein is required for synthesis of the leading strand at the replication fork (33) and is necessary for entry of cells from $G_{1}$ into $S$ $(34,35)$. PCNA-labeled nuclei identify cells in late $G_{1}$ and early $S$ phases of the cell cycle (10). It is interesting that PCNA is also expressed during DNA repair and the protein has been found to increase the extent of nucleotide excision by potentiating the catalytic function of the excision repair enzyme (36).

The marked increase in PCNA expression as early as $2 \mathrm{~d}$ after ischemia indicates that the repair process is initiated by then and that induction of movement through the cell cycle has occurred. These results strongly suggest that proximal epithelial cells undergo proliferation in response to ischemia. In preliminary studies we have also found that a large number of cells in the $\mathrm{S} 3$ segment in fact do undergo mitosis. The observation that PCNA expression is greatest in the S3 segment of the proximal tubule is consistent with the fact that most of the damage associated with ischemia in this model in the rat is seen in this tubular segment. In addition, because PCNA may be involved in DNA repair, it is possible that PCNA expression will potentiate recovery of damaged cells as well as reflect mitogenesis and resultant replacement of dead epithelial cells.

Postischemic recovery may recapitulate certain aspects of renal development $(25,37)$. Vimentin, an intermediate filament protein, is usually only expressed in mesenchymal cells.

Figure 10. Cryostat sections of the outer medulla of $(a$ and $b)$ postischemic and $(c)$ control contralateral kidneys taken $2 \mathrm{~d}$ after reperfusion and stained for the presence of clusterin. (a) Both thick ascending limb $(T A L)$ cells and cells of the $\mathrm{S} 3$ segment of the proximal tubule stain intensely although the pattern of staining is different. The staining pattern in S3 cells was diffuse throughout the cytoplasm, whereas that of the TAL cells was apical and punctate. Many positively stained cells were present in the S3 tubule lumen, possibly representing dead or damaged cells. CD $=$ collecting ducts. Bar, $40 \mu \mathrm{m}$. (b) In some of the S3 cells, a bright spot of clusterin staining was observed. This pattern was not seen in distal tubule cells. Bar, $40 \mu \mathrm{m}$. (c) In the outer medulla (inner stripe) of the control contralateral nonischemic kidney there was a small amount of granular clusterin staining in thick ascending limb cells. Bar, $40 \mu \mathrm{m}$. 

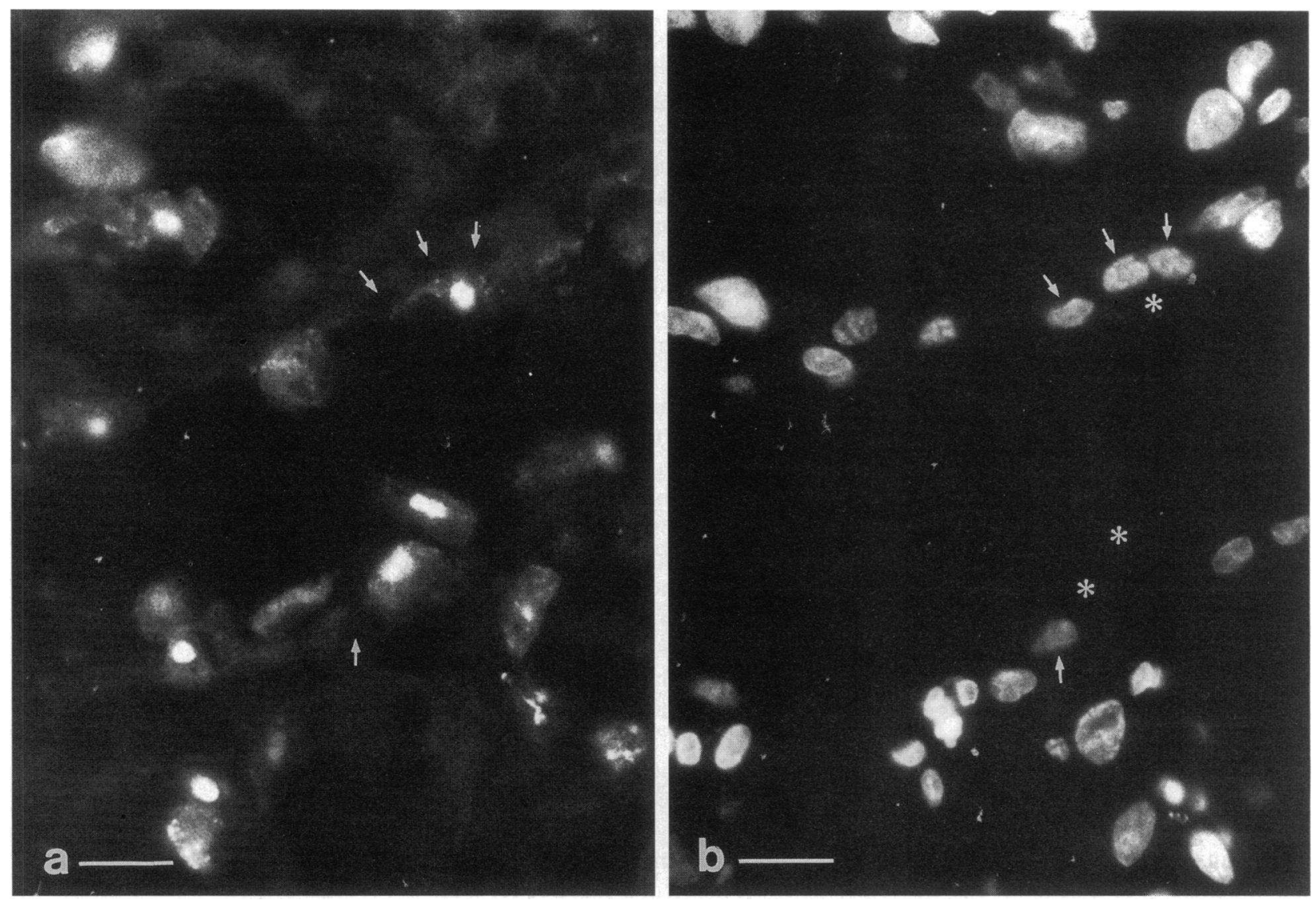

Figure 12. Higher-power micrograph of a section of postischemic kidney incubated with $(a)$ anti-clusterin antibody or $(b)$ the Hoechst stain to identify nuclei. Arrows mark the nuclei in both $a$ and $b$ clearly demonstrating that the dense spots of clusterin staining in cells of the S3 segment seen in $a$ do not coincide with the cell nucleus stained in $b$. Asterisks (*) indicate clusterin-stained material. Arrows mark corresponding nuclei in $a$ and $b$. Bar, $20 \mu \mathrm{m}$.

Those parts of the nephron, which are derived from metanephrogenic mesenchyme, express vimentin in their early stages of development, after which the expression of vimentin is turned off and cytokeratin expression is turned on. In the normal adult kidney, the tubular epithelial cells do not express vimentin (38). Vimentin is expressed, however, in renal cell carcinomas, especially in those tumors that are most poorly differentiated (39). Our finding of intense staining of proximal tubule cells with antibodies to vimentin at 2 and $5 \mathrm{~d}$ postischemia indicates that the regeneration/repair process is associated with a reversion to a less differentiated phenotype. The segmental and cellular pattern of vimentin expression reflects a specific cellular response ( $\mathrm{S} 3 \gg \mathrm{S} 1, \mathrm{~S} 2$ ) to ischemia, and not only a segmental or regional variability in the degree of hypoxic exposure. The expression of vimentin and PCNA in most cells of the epithelium suggests that many, if not all, surviving S3 cells have the ability to divide and dedifferentiate and that this capacity is not limited to just a few "stem cells." Vimentin has also been identified in regenerating S3 segment cells after damage due to toxin exposure (40). When interpreting data from experiments using toxins to induce renal injury, however, it is generally not possible to distinguish effects due to the toxin itself from effects characteristic of the tissue repair response to cellular injury and necrosis.

Our findings with c-Fos are somewhat surprising but consistent with our prior observations with Egr-1 (25). The genes encoding these proteins, $c$-fos and $E g r-1$, belong to the family of immediate-early genes, whose expression is induced with growth stimuli in a manner independent of protein synthesis. Their expression frequently marks the entry of cells from the $G_{0}$ to the early $G_{1}$ phase of the cell cycle. The time course of increase in expression of the c-Fos protein is consistent with our previous identification of the time course of increase in total kidney c-fos mRNA levels after ischemia (23). It is interesting, however, that the $\mathrm{S} 3$ proximal nephron segments undergoing most of the proliferation, as revealed by the PCNA expression, are not the primary site of c-Fos protein expression although c-Fos is clearly detectable in some of these cells. As with the Egr-1 protein, the c-Fos protein is primarily expressed in the distal nephron, in regions of the nephron where there is very little PCNA expression. It is possible that the expression of the $c$-fos gene is related to stimuli not involved in the growth response. In addition to growth stimuli, immediate-early genes can also be induced by cellular depolarization and mechanical force in vitro, and by seizures or excitation of the visual cortex in vivo, i.e. in situations where cells will not enter the cell cycle but remain in $\mathrm{G}_{0}$ phase (41). Interruption of blood flow for 40 min is a rather dramatic intervention in the physiology of the whole organ with profound metabolic alterations. In contrast, the cellular expression of the immediate-early genes $c$-fos, Egr$I(23)$, and $J E(28)$ is very specific and can be seen primarily or exclusively in the distal tubule. Perhaps the expression of these 

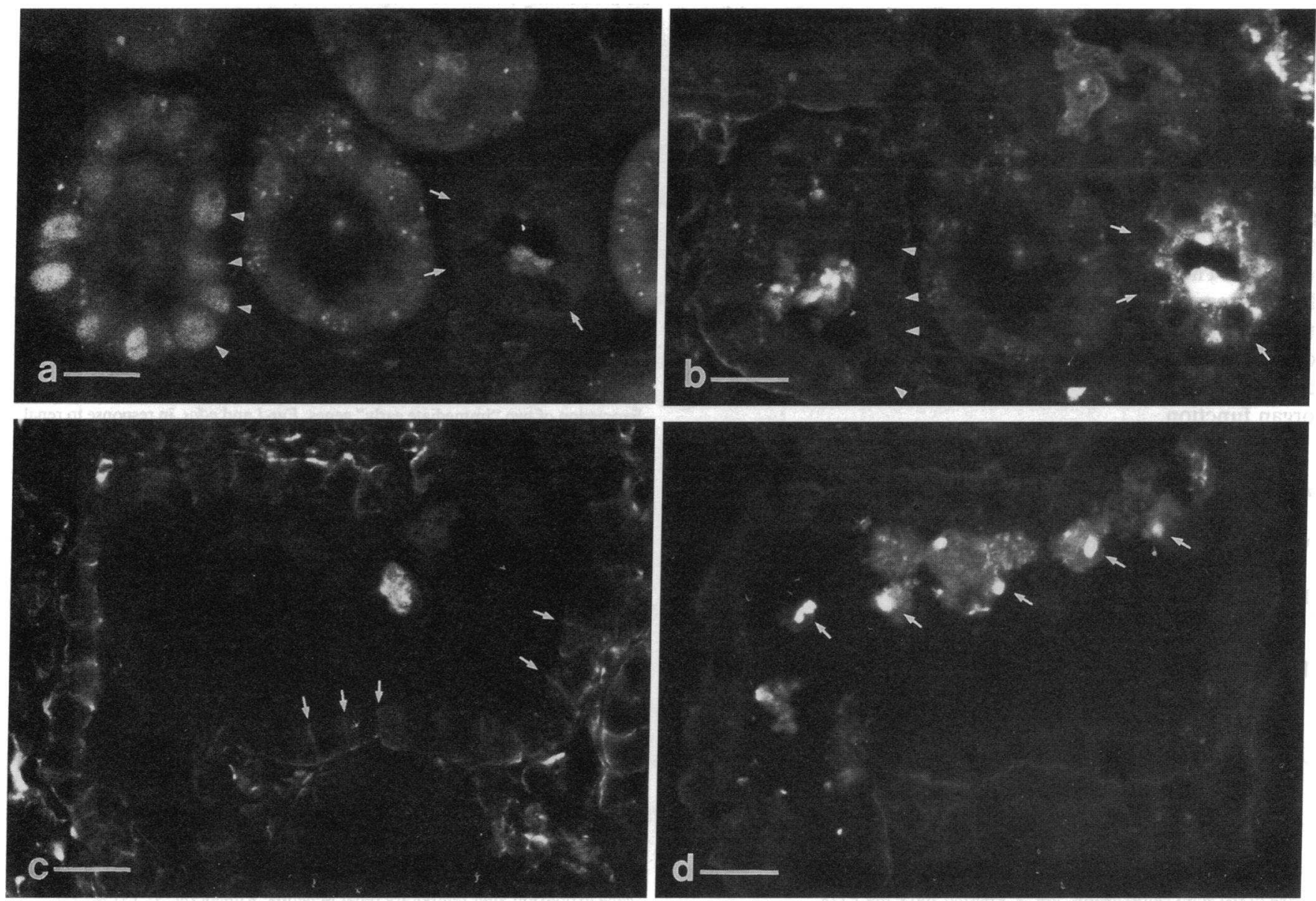

Figure 13. Two cryostat sections of the outer medulla of postischemic kidneys taken $2 \mathrm{~d}$ after reperfusion and stained for the presence of $(a)$ PCNA and $(b)$ clusterin or $(c)$ vimentin and $(d)$ clusterin. Cells in the S3 segment of the proximal tubule whose nuclei stain positively for PCNA as shown in $a$ are negative for clusterin as shown in $b$. These cells are marked by heavy arrows. As marked by the lighter arrows, cells that are positive for clusterin in $b$ are negative for PCNA in $a$. In $c$, arrows mark lateral aspects of a few of the many cells in this S3 segment that stain positively for vimentin. None of these vimentin-positive cells stain positively with antibodies to clusterin as shown in $d$. Debris in the lumen of the $\mathrm{S} 3$ segment, delineated by arrows in $d$, stains strongly with the clusterin antibodies but does not stain positively with antibodies to vimentin as shown in $c$. Bars $=40 \mu \mathrm{m}$.

immediate-early genes may confer a protective effect on the cell.

Understanding the cellular control of differentiation and growth, and how factors controlling differentiation and growth are modulated with ischemia, should provide insight into the determinants of recovery from acute renal failure. By identifying the appearance and disappearance of developmentally regulated proteins in the postischemic kidney it may be possible to characterize a developmental paradigm that the injured tissue recapitulates. The success of the recovery process may depend upon the ability of the kidney to mount an ordered sequence of genetic events designed to replace damaged and/or dead epithelial cells, thus resulting in restoration of the differentiated phenotype by cells that are nonlethally injured. This "recovery program" may be critical for restoration of epithelial functional and structural integrity.

The role of clusterin in cell injury and repair is incompletely understood. It may play a role in programmed cell death (apoptosis) (11), but it is also expressed in fully differentiated viable adult tissues. The steady-state levels of clusterin mRNA, as examined by Northern blot analysis increase dra- matically after renal ischemia, while its mRNA can barely be detected in the normal adult kidney (29). At 1-5 d postischemia clusterin expression is localized primarily to the distal nephron and S3 proximal segments. In the distal tubule the staining is in a granular cytosolic pattern, whereas in the S3 segment the pattern is generally diffuse with some large condensed patches of staining. This latter pattern is reminiscent of the cytosolic condensation seen with apoptosis (42) and one possibility is that this pattern identifies cells undergoing programmed cell death. The fact that none of the cells with this pattern of clusterin staining expressed vimentin or PCNA indicates that these clusterin-positive $S 3$ cells do not participate in the dedifferentiation and mitogenic response that most of the viable S3 cells undergo in the postischemic period. This, together with the fact that large casts of uniformly clusterin-positive cellular debris were seen in the lumen of the $S 3$ segments supports the view that cells staining with anti-clusterin antibodies were nonviable. The implications of the granular apical clusterin staining in the distal nephron are not clear.

In summary the appearance of PCNA and vimentin in S3 proximal tubule cells suggests that viable epithelial cells dedif- 
ferentiate and progress through the cell cycle to restore epithelial integrity and cell function. Like Egr-1, c-Fos is detectable early in the postischemic period primarily in thick ascending limb cells which are not as susceptible to damage in this model of ischemia. c-Fos is also expressed in some S3 cells where it may identify cells in early G1. Clusterin expression is seen in the $\mathbf{S} 3$ proximal cells as well as the distal tubule cells but the pattern of immunocytochemical staining is quite different and the pattern in the S3 segment may predict cell death of proximal cells. These data support the view that mature renal epithelial cells can be progenitor cells and they provide insight into the diverse genetic program that is initiated in the kidney recovering from acute ischemic injury revealing that mitogenesis and dedifferentiation are likely to be critical for restoration of organ function.

\section{Acknowledgements}

We thank John Lydon for photographic work.

The authors are supported by National Institutes of Health grants DK 39773, DK38452, and NS 10828.

\section{References}

1. Bonventre, J. V., A. Leaf, and C. D. Malis. 1988. Nature of the cellular insult in ischemic acute renal failure. In Acute Renal Failure. B. M. Brenner and J. M. Lazarus, editors. Churchill-Livingstone, Inc., New York. 3-43.

2. Bonventre, J. V. 1993. Mechanisms of ischemic acute renal failure. Kidney Int. 43:1160-1178.

3. Corwin, H. L., and J. V. Bonventre. 1989. Factors influencing survival in acute renal failure. Semin. Dial. 2:220-225.

4. Molitoris, B. A. 1991. Ischemia-induced loss of epithelial polarity: potential role of the actin cytoskeleton. Am. J. Physiol. 260:F769-F778.

5. Molitoris, B. A., R. H. Dahl, and S. A. Falk. 1989. Ischemic-induced loss of epithelial polarity: role of the tight junction. J. Clin. Invest. 84:1334-1339.

6. Bayati, A., K. Nygren, Ö. Källskog, and M. Wolgast. 1989. The long-term outcome of post-ischaemic acute renal failure in the rat. II. A histopathological study of the untreated kidney. Acta Physiol. Scand. 138:35-47.

7. Arendshorst, W. J., W. F. Finn, and C. W. Gottschalk. 1975. Pathogenesis of acute renal failure following temporary renal ischemia in the rat. Circ. Res. 37:558-568.

8. Mason, J., C. Olbricht, T. Takabatake, and K. Thurau. 1977. The early phase of experimental acute renal failure. I. Intratubular pressure and obstruction. Pflügers Arch. Eur. J. Physiol. 370:153-163.

9. Thurau, K., and J. W. Boylan. 1976. Acute renal success: The unexpected logic of oliguria in acute renal failure. Am. J. Med. 61:308-315.

10. Connolly, K. M., and M. S. Bogdanffy. 1993. Evaluation of proliferating cell nuclear antigen (PCNA) as an endogenous marker of cell proliferation in rat liver: A dual-stain comparison with 5-bromo-2'-deoxyuridine. J. Histochem. Cytochem. 41:1-6.

11. Buttyan, R. 1991. Genetic response of prostate cells to androgen deprivation: insights into the cellular mechanism of apoptosis. In Apoptosis: The Molecular Basis of Cell Death. L. D. Tomei and F. O. Cope, editors. Cold Spring Harbor Laboratory Press, Cold Spring Harbor, NY. 157-173.

12. Tsuruta, J. K., K. Wong, I. B. Fritz, and M. D. Griswold. 1990. Structura analysis of sulphated glycoprotein 2 from amino acid sequence: relationship to clusterin and serum protein 40,40. Biochem. J. 268:571-578.

13. Jenne, D. E., and J. Tschopp. 1989. Molecular structure and functiona characterization of a human complement cytolysis inhibitor found in blood and seminal plasma: Identity to sulfated glycoprotein 2 , a constituent of rat testes fluid. Proc. Natl. Acad. Sci. USA. 86:7123-7127.

14. Palmer, D. J., and D. L. Christie. 1990. The molecular structure of glycoprotein III from bovine adrenal medullary chromaffin granules. Sequence similarity with human serum protein-40,40 and rat Sertoli cell glycoprotein 2 . J. Biol. Chem. 265:6617-6623.

15. Malis, C. D., J. Y. Cheung, A. Leaf, and J. V. Bonventre. 1983. Effects of verapamil in models of ischemic acute renal failure in the rat. Am. J. Physiol. 245:F735-F742.

16. Kelly, K. J., W. W. Williams, R. B. Colvin and J. V. Bonventre. 1994. Antibody to intercellular adhesion molecule 1 protects the kidney against ischemic injury. Proc. Natl. Acad. Sci. USA. 91:812-816.

17. Waseem, N. H., and D. P. Lane. 1990. Monoclonal antibody analysis of the proliferating cell nuclear antigen (PCNA): structural conservation and the detection of a nucleolar form. J. Cell Sci. 96:121-129.

18. Osborn, M., E. Debus, and K. Weber. 1984. Monoclonal antibodies specific for vimentin. Eur. J. Cell Biol. 34:137-143.

19. Adamkiewicz, J., H.-J. Brüller, H. Gausepohl, R. Frank, and R. Müller. 1990. Mapping of functional domains in Fos and Jun proteins using epitope-specific antibodies. Oncogene. 5:525-533.

20. Grima, J., I. Zwain, R. A. Lockshin, C. W. Bardin, and C. Y. Cheng. 1990. Diverse secretory patterns of clusterin by epididymis and prostate/seminal vesicles undergoing cell regression after orchiectomy. Endocrinology. 126:29892997.

21. Brown, D., A. Kunz, A. Wohlwend, J.-D. Vassalli, and L. Orci. 1983. Ultrastructural detection of glycocalyx heterogeneity in convoluted and straight proximal tubules of rat kidney, using lectin gold complexes. C. R. Acad. Sci. Paris. 297:501-506.

22. Brown, D., X. L. Zhu, and W. S. Sly. 1990. Localization of membrane-associated carbonic anhydrase type IV in kidney epithelial cells. Proc. Natl. Acad. Sci. USA. 87:7457-7461.

23. Ouellette, A. J., R. A. Malt, V. P. Sukhatme, and J. V. Bonventre. 1990 Expression of two "immediate early" genes, Egr-l and $c$-fos, in response to renal ischemia and during compensatory renal hypertrophy in mice. J. Clin. Invest. 85:766-771.

24. Humes, H. D., D. A. Cieslinski, T. M. Coimbra, J. M. Messana, and C. Galvao. 1989. Epidermal growth factor enhances renal tubule cell regeneration and repair and accelerates the recovery of renal function in postischemic acute renal failure. J. Clin. Invest. 84:1757-1761.

25. Bonventre, J. V., V. P. Sukhatme, M. Bamberger, A. J. Ouellette, and D. Brown. 1991. Localization of the protein product of the immediate early growth response gene, Egr-I, in the kidney after ischemia and reperfusion. Cell Regul. 2:251-260.

26. Rosenberg, M. E., and M. S. Paller. 1991. Differential gene expression in the recovery from ischemic renal injury. Kidney Int. 39:1156-61.

27. Polla, B. S., N. Mili, and J. V. Bonventre. 1991. Les proteines de stress: quelles implications en nephrologie. Nephrologie. 12:119-123.

28. Safirstein, R., J. Megysesi, S. J. Saggi, P. M. Price, M. Poon, B. J. Rollins, and M. B. Taubman. 1991. Expression of cytokine-like genes JE and KC is increased during renal ischemia. Am. J. Physiol. 261:F1095-F1101.

29. Witzgall, R., E. O'Leary, R. Gessner, A. J. Ouellette, and J. V. Bonventre. 1993. Kid-1, a putative renal transcription factor: regulation during ontogeny, and in response to ischemia and toxic injury. Mol. Cell. Biol. 13:1933-1942.

30. Safirstein, R., P. M. Price, S. J. Saggi, and R. C. Harris. 1990. Changes in gene expression after temporary renal ischemia. Kidney Int. 37:1515-1521.

31. Bravo, R., R. Frank, P. A. Blundell, and H. Macdonald-Bravo. 1987. Cyclin/PCNA is the auxiliary protein on DNA polymerase- $\delta$. Nature (Lond.). 326:515-517.

32. Prelich, G., C.-K. Tan, M. Kostura, M. B. Mathews, A. G. So, K. M. Downey, and B. Stillman. 1987. Functional identity of proliferating cell nuclear antigen and a DNA polymerase- $\delta$ auxiliary protein. Nature (Lond.). 326:517520.

33. Prelich, G., and B. Stillman. 1988. Coordinated leading and lagging strand synthesis during SV40 DNA replication in vitro requires PCNA. Cell. 53:117126.

34. Jaskulski, D., J. K. DeRiel, W. E. Mercer, B. Calabretta, and R. Baserga. 1988. Inhibition of cellular proliferation by antisense oligonucleotides to PCNA cyclin. Science (Wash. DC). 240:1545-1546.

35. Liu, Y.-C., R. L. Marraccino, P. C. Keng, R. A. Bambara, E. M. Lord, W.-G. Chou, and S. B. Zain. 1898. Requirement for proliferating cell nuclear antigen expression during stages of the chinese hamster ovary cell cycle. Biochemistry. 28:2967-2974.

36. Nichols, A. F., and A. Sancar. 1992. Purification of PCNA as a nucleotide excision repair protein. Nucleic Acids Res. 20:2441-2446.

37. Bacallao, R., and L. G. Fine. 1989. Molecular events in the organization of renal tubular epithelium: from nephrogenesis to regeneration. Am. J. Physiol. 1989:F913-F924.

38. Holthöfer, H., A. Miettinen, V.-P. Lehto, E. Lehtonen, and I. Virtanen. 1984. Expression of vimentin and cytokeratin types of intermediate filament proteins in developing and adult human kidneys. Lab. Invest. 50:552-559.

39. Dierick, A.-M., M. Praet, H. Roels, P. Verbeeck, C. Robyns, and W. Oosterlinck. 1991. Vimentin expression of renal cell carcinoma in relation to DNA content and histological grading: a combined light microscopic, immunocytochemical and cytophotometrical analysis. Histopathology. 18:315-322.

40. Wallin, A., G. Zhang, T. W. Jones, S. Jaken, and J. L. Stevens. 1992. Mechanism of nephrogenic repair response. Studies on proliferation and vimentin expression after ${ }^{32} \mathrm{~S}-1,2$-dichlorovinyl-L-cysteine nephrotoxicity in vivo and in cultured proximal tubule epithelial cells. Lab. Invest. 66:474-484.

41. Sheng, M., and M. E. Greenberg. 1990. The regulation and function of $c$-fos and other immediate early genes in the nervous system. Neuron. 4:477-485.

42. Kerr, J. F. R., and B. V. Harmon. 1991. Definition and incidence of apoptosis: an historical perspective. In Apoptosis: the Molecular Basis of Cell Death. L. D. Tomei and F. O. Cope, editors. Cold Spring Harbor Laboratory Press, Cold Spring Harbor, NY. 5-29. 